\title{
Про деякі тактичні аспекти застосування радіочастотної абляції в лікуванні варикозної хвороби нижніх кінцівок в амбулаторних умовах
}

\begin{abstract}
Мета роботи: дати клінічну оцінку результатам застосування радіочастотної моноабляції в лікуванні варикозної хвороби нижніх кінцівок із метою розширення показань до її виконання в амбулаторних умовах.

Матеріали і методи. Впродовж 2016-2019 рр. під спостереженням перебувало 928 пацієнтів із варикозною хворобою С2 - С4 за класифікацією СЕАР, із них жінок - 538 (58 \%), чоловіків - 390 (42 \%), вік хворих від 18 до 72 років. Для усунення вертикального скиду використовували РЧА за методикою VNUS - Closure FAST, за допомогою апарата COVIDIEN фipми Medtronics.

Результати досліджень та їх обговорення. УЗД стану стовбура підшкірних вен показало, що після РЧ моноабляції реканалізація вен через рік настала із 928 хворих у 46 (5 \%) та у 84 (9 \%) пацієнтів через три роки. Достовірної різниці в реканалізації через 1 та 3 роки в пацієнтів із діаметрами ВПВ понад 16 мм не спостерігали. Встановлено, що через 3 місяці після виконання РЧ моноабляції інволюція притоків сафенних вен наступила у 538 (58 \%) хворих. У 78 (8,4 \%) хворих одночасно виконано РЧА з ЕХО склеротерапією перфорантних вен на гомілці 3 \% розчином полідоканолу. У інших 312 (33,6 \%) пацієнтів, у яких інволюція притоків сафенних вен на гомілці не наступила (при повній оклюзії стовбура великої підшкірної вени після РЧА), застосовано відтерміновані мініінвазівні втручання. Зокрема, мініфлебектомію виконано у 236 хворих за стандартною технологією. У 76 пацієнтів для усунення варикозно трансформованих притоків сафенних вен використано комбінацію мініфлебектомії з облітерацією неспроможних перфорантних вен шляхом пінної ЕХО-склеротерапії або РЧА. Таким чином, у більшості пацієнтів (58 \%) РЧ моноабляція тільки стовбура великої підшкірної вени здатна привести до інволюції притоків сафенних вен на гомілці. Це дає можливість за рахунок малотравматичності, скорочення часу операції широко використовувати РЧ моноабляцію у пацієнтів похилого віку та за наявності у хворих поліморбідної супутньої патології в амбулаторних умовах.
\end{abstract}

Ключові слова: радіочастотна абляція вен; мініфлебектомія; ЕХО-склеротерапія.

Постановка проблеми і аналіз останніх досліджень та публікацій. Застосування радіочастотної абляції (РЧА) у лікуванні варикозної хвороби нижніх кінцівок (ВХНК) вважають одним із ефективних методів у функціональному та косметичному плані $[1,2,3]$. Слід зазначити, що впродовж останніх років у світі спостерігається чітка тенденція до виконання операцій флебологічного профілю, в тому числі РЧА, в амбулаторних умовах. Для цього визначені загальномедичні, хірургічні та соціальні критерії $[4,5]$. Однак, завдяки мінімальній інтервенційності, короткотривалості та відсутності потреби у загальному знеболенні, такі операції стали доступними не тільки для молодих осіб, але і для пацієнтів похилого віку, а також у випадках наявності супутніх соматичних захворювань [6-9].

Вибір шляхів усунення видимих варикозно трансформованих колатералей басейну сафенних вен досі $\epsilon$ предметом обговорення у світі та в Україні. В умовах “хірургії одного дня” (офісної хірургії), де регулярно впроваджуються нові технології лікування варикозної хвороби, зокрема гемодинамічні (ASVAL, CHIVA), що передбачають операції на розширених колатеральних венах, створюється ситуація невизначеності у плані вибору методу мініінвазивних операцій. Тому виникають дискусійні питання у плані здійснювати тільки моноабляцію для усунення вертикального рефлюксу чи виконувати одночасно з моноабляцією операції на розширених притоках сафенних вен, або здійснювати їх відтермінування після клінічного та УЗ аналізу наслідків моноабляції в післяопераційному періоді.

Ці питання залишаються відкритими і для пацієнтів похилого віку та пацієнтів із супутніми соматичними захворюваннями. Одномоментна стратегія лікування варикозної хвороби, спрямована на максимальне видалення варикозних вен, не викликає сумніву. Однак поетапне усунення патології в таких пацієнтів може бути альтернативою. Це потребує додаткового дослідження для оцінки результатів РЧА $[10,11]$. Тому відповідь на питання, чи вирішує тільки радіочастотна моноабляція проблему лікування варикозної хвороби в амбулаторних умовах, чи слід доповнювати іï додатковими мініінвазивними операціями є актуальною.

Мета роботи: дати клінічну оцінку результатам застосування радіочастотної моноабляції у лікуванні варикозної хвороби нижніх кінцівок із метою розширення показань до ії виконання в амбулаторних умовах. 
Матеріали і методи. Впродовж 2016-2019 рр. у медичному центрі “Відновлення” (м. Житомир) та у “Стаціонарі одного дня" на базі медичного центру “Паракліт” (м. Тернопіль) під спостереженням, після виконання РЧА, перебувало 928 пацієнтів із варикозною хворобою, з клінічними стадіями С2 - С4 ( класифікація СЕАР ). Із них жінок - 538 (58 \%), чоловіків - 390 (42 \%). За віком, згідно з віковою класифікацією Всесвітньої організації охорони здоров'я, хворих розподілили наступним чином: 25-44 роки (молодий вік) 389 (41,9 \%) пацієнтів; 44-60 років (середній вік) - 301 (32,2 \%) хворих; 60-75 (похилий вік) - 179 (19,3 \%) пацієнтів; старших 75 років (старий вік) 59 (6,4 \%) хворих. Середній індекс коморбідності

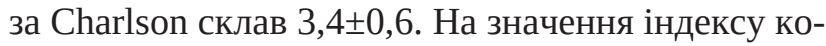
морбідності вплинув вік хворих (25,7 \% більше 60 років) та наявність однієї чи двох супутніх захворювань (переважно гіпертонічної хвороби, IXC, цукрового діабету, ХОЗЛ тощо).

Усім хворим проведено ультразвукову діагностику для встановлення флебогемодинамічних порушень у кінцівці. УЗД венозної системи нижніх кінцівок виконували на апараті Mindray Z5 (Mindray Bio - Medical Electronics, CO, Китай) із датчиком частотою 5-14 МГц та відповідним стандартним пакетом програмного забезпечення вказаної фірми для дослідження венозної системи. Пацієнтів обстежували у другій половині дня у вертикальному та горизонтальному положеннях. Під час ультразвукового дослідження оцінювали наявність кровотоку у венах, діаметри та форми просвіту вен, їх деформацію та мішкоподібну трансформацію, товщину стінок, однорідність, еластичність клапанів, їх функцію під час навантажувальних гідростатичних проб, наявність рефлюксу крові, тривалість ретроградного потоку по венозних магістралях, поширеність останнього на перфорантні вени, стан сафено-феморального та сафено-поплітеального з'єднання. Особливу увагу приділяли локалізації перфорантних вен, визначенню їх діаметра та тривалості рефлюксу венозної крові в них. Клінічні дані та дані УЗД венозної системи нижніх кінцівок були визначальними у виборі методів усунення венозних рефлюксів.

Для усунення вертикального скиду застосовували РЧА за методикою VNUS - Closure FAST, з використанням апарата COVIDIEN фірми Medtronics. Необхідно зазначити, що у 242 (26,1 \%) хворих РЧА стовбура ВПВ була виконана при його діаметрі $(16 \pm 0,4)$ мм.

850 пацієнтам виконано лише РЧ моноабляцію основного стовбура великої підшкірної вени, а у 78 хворих застосували РЧ моноабляцію із си- мультанною мініфлебектомією та ЕХО-склеротерапією при вираженій варикозній трансформації вени Leonardi та недостатності перфорантних вен групи Cockett або Boid (при їх діаметрі більше 4 мм та рефлюксі крові понад 0,5 с).

Мініфлебектомію виконували за стандартною технологією без ушивання проколів шкіри, з використанням ранових пов'язок типу Steril Strip. Обробку неспроможних перфорантів здійснювали шляхом пінної ЕХО-склеротерапії 3 \% розчином полідоканолу з обов'язковою попередньою тумесценцією та промиванням зони розташування перфорантної вени охолодженим до $+1-3{ }^{\circ} \mathrm{C}$ фізіологічним розчином, з метою її ангіоспазму. В 9 випадках виконано РЧА перфорантної вени стилетним електродом 6 Fr $(2,0 \mathrm{~mm})$ за стандартною методикою.

Ефективність оцінювали за клінічною та УЗ картиною до та після операцій. Інтенсивність больового синдрому визначали за цифровою рейтинговою шкалою (Numerical Rating Scale, NRS). Для оцінки клінічної тяжкості венозних захворювань застосовували шкалу VCSS (venous clinical severity score), показник венозних сегментарних захворювань - VSDS (venous segmental disease score), фізичну активність за шкалою VDS (venous disability score). Об'єктивну оцінку тяжкості хронічного захворювання вен проводили із застосуванням системи оцінки тяжкості венозної патології VSS (venous severity scoring). Для об’єктивності оцінки впливу операцій на VSS та якість життя, хворі були розділені на 2 групи: 1 група - 538 хворих, яким виконано тільки РЧА; 2 група - 78 пацієнтів, яким виконана одночасно РЧА із симультативними мініінвазивними операціями.

Оцінку якості життя (ЯЖ) проводили з використанням загального опитувальника якості життя SF-36 (“Health Status Survey”). Він дає можливість оцінити динаміку відновлення фізичного, психологічного та соціального функціонування хворих після хірургічного втручання. Цей тест складається з 36 питань, які формують 8 шкал: фізичне функціонування (Physical Functioning - PF), рольове функціонування, яке зумовлено фізичним станом (Role-Physical Functioning - RP), інтенсивність болю (Bodily pain - BP), загальний стан здоров'я (General Health - GH) - життєва активність (Vitality - VT), соціальне функціонування (Social Functioning - SF), рольове функціонування, зумовлене емоційним станом (Role-Emotional - RE), психічне здоров'я (Mental Health - MH). Хворі відповідали на запитання анкети через 3 місяці після проведеного хірургічного лікування. Відповіді на запитання оцінювали за номінальною 
шкалою від 0 до 5 балів, після чого визначали загальний показник для кожного пункту.

Статистичну обробку цифрових даних здійснювали методом варіаційної статистики. Достовірність різниці середніх величин та їхніх похибок оцінювали за критеріями Стьюдента-Фішера. Обробку цифрових даних проводили за методом Стьюдента в програмі Exel на персональному комп’ютері. Достовірність змін визнавалась за вірогідності помилки р менше або рівне 0,05 ( $<<0,05)$.

Результати досліджень та їх обговорення. УЗД стану стовбура підшкірних вен показало, що після РЧА його реканалізація через рік спостерігалася у 46 (5 \%) хворих та у 84 (9 \%) пацієнтів через три роки. Достовірної різниці в реканалізації в пацієнтів із діаметрами ВПВ понад 16 мм через 1 та 3 роки не спостерігалося.

Через 3 місяці після виконання тільки РЧ моноабляції ми встановили, що інволюція притоків розширених колатеральних вен настала у 538 (58 \%) хворих. Таким чином, у цих хворих виконання додаткових мінінвазивних операцій на колатеральних венах вдалося уникнути, що є важливим чинником при збільшеному індексі коморбідності у певної категорії хворих.

У інших 312 (33,6 \%) пацієнтів, у яких інволюція притоків великої підшкірної вени на гомілці не наступила (при повній оклюзї̈ стовбура великої підшкірної вени після РЧА), після 3 місяців спостереження застосовано відтерміновані мініінвазивні втручання. Зокрема, мініфлебектомію виконано у 236 хворих за стандартною технологією, без ушивання проколів шкіри 3 використанням ранових пов’язок типу Steril Strip. У 76 пацієнтів для усунення варикозно змінених притоків сафенних вен використано комбінацію мініфлебектомії із облітерацією неспроможних перфорантних вен шляхом пінної ЕХО-склеротерапії. В 9 випадках виконано РЧА перфорантних вен стилетним електродом 6 Fr (2,0 mm) за стандартною методикою.

Оцінка клінічної тяжкості до операції - VCSS (C) у всіх хворих дорівнювала $(6,1 \pm 0,2)$ бала, показника венозних сегментарних захворювань $\operatorname{VSDS}(\mathrm{A})$ - $(1,09 \pm 0,12)$ бала, фізичної активності VDS (D) - $(1,05 \pm 0,10)$ бала. В середньому тяжкість хронічного захворювання вен VSS (C+A+D) становила $(8,47 \pm 0,40)$ бала. Через один місяць після операції спостерігали достовірне (р <0,05) зменшення тяжкості захворювання в першій групі хворих в 1,77 раза, в другій - в 1,63 раза (р <0,05). Через 3 місяців показники VSS становили, відповідно, в 2,61 та 2,32 раза менше, а через 6 місяців ці показники зменшились, відповідно, в 3,79, та 3,64 раза (р < 0,05). В подальшому, через 12 місяців, суттєвої різниці показниках за шкалою VSS не відбулося (рис. 1).

Таким чином, ми встановили, що після виконання тільки РЧА відбулося статистично значуще $(\mathrm{p}<0,05)$ зниження тяжкості захворювання порівняно з комбінацією РЧА з іншими мініінвазивними операціями.

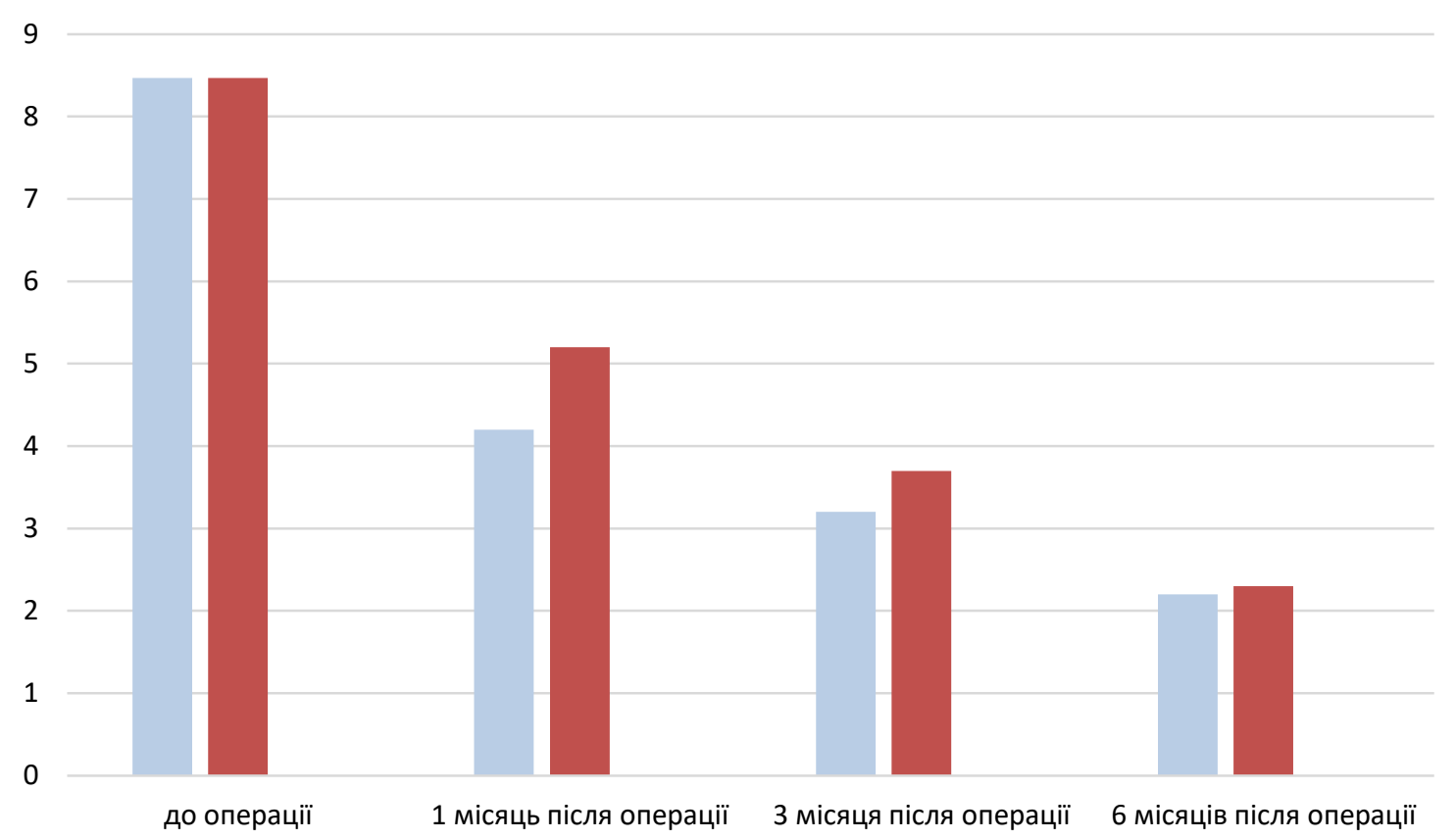

Рис. 1. Тяжкість XЗВ за шкалою VSS у динаміці після операції. 
Рівень больових відчуттів у ранньому післяопераційному періоді при застосуванні тільки РЧ моноабляції був значно нижчим - $(2,0 \pm 0,1)$ бала, ніж при комбінації РЧ моноабляції із симультанними операціями - $(3,0 \pm 0,3)$ бала $(\mathrm{p}<0,05)$.

Проведено порівняльну оцінку ЯЖ після різних методів операції через один місяць після їх виконання (табл. 1). Так, ЯЖ у всіх прооперованих хворих значно покращилася, ніж до операції. Однак після виконання тільки РЧА за всіма шкалами у хворих прослідковуються кращі показниками ЯЖ, ніж у другій та третій групах хворих. Це пояснюється незначною травматичністю цієї операції, що безпосередньо впливає на ці показники.

Таблиця 1. Якість життя хворих через один місяць після застосування різних методів операцій при варикозній хворобі

\begin{tabular}{||l|c|c|c|c||}
\hline \multirow{2}{*}{ Шкали } & \multicolumn{3}{|c||}{ Методи лікування варикозної хвороби } \\
\cline { 2 - 5 } & $\begin{array}{c}\text { до операції } \\
(\mathrm{n}=55)\end{array}$ & $\begin{array}{c}\text { РЧА } \\
(\mathrm{n}=98)\end{array}$ & $\begin{array}{c}\text { РЧА+мініінвазивні операції } \\
(\mathrm{n}=78)\end{array}$ & $\begin{array}{c}\text { РЧА+відтерміновані } \\
\text { мініінвазивні операції (n=82) }\end{array}$ \\
\hline PF & $79,6 \pm 0,8$ & $95,6 \pm 0,4^{* *}$ & $89,8 \pm 0,6^{* *}$ & $91,2 \pm 0,7^{* *}$ \\
\hline RP & $75,2 \pm 0,7$ & $86,7 \pm 0,6^{* *}$ & $82,4 \pm 0,7^{* *}$ & $83,6 \pm 0,4^{* *}$ \\
\hline BP & $84,7 \pm 0,3$ & $98,5 \pm 0,7^{* *}$ & $89,4 \pm 0,9 * *$ & $92,7 \pm 0,6^{* *}$ \\
\hline GH & $74,3 \pm 0,6$ & $93,7 \pm 0,3^{*}$ & $92,05 \pm 0,7^{*}$ & $91,8 \pm 0,3^{*}$ \\
\hline VT & $82,5 \pm 0,4$ & $95,6 \pm 0,5^{*}$ & $90,05 \pm 0,4^{*}$ & $92,4 \pm 0,5^{*}$ \\
\hline ST & $81,7 \pm 0,6$ & $98,7 \pm 0,8^{*}$ & $92,08 \pm 0,1^{*}$ & $95,6 \pm 0,7^{*}$ \\
\hline RE & $77,6 \pm 0,8$ & $98,3 \pm 0,7^{*}$ & $89,8 \pm 0,7^{*}$ & $94,8 \pm 0,3^{*}$ \\
\hline MH & $75,9 \pm 0,5$ & $94,8 \pm 0,1^{*}$ & $90,1 \pm 0,6^{*}$ & $92,5 \pm 0,4^{*}$ \\
\hline \hline
\end{tabular}

Між показниками у хворих до операції та після операції встановлено достовірну різницю: * - p<0,05; ** - p<0,01.

Також слід вказати на кращу динаміку відновлення фізичного, психологічного та соціального функціонування хворих після РЧА та після відтермінованих мініінвазивних операцій порівняно з одночасним виконанням РЧА та мініінвазивними операціями. Це відкриває перспективи до виконання двохетапних операцій у певної категорії хворих із високим індексом коморбідності.

Аналіз результатів лікування варикозної хвороби нижніх кінцівок свідчить, що РЧ моноабляція тільки стовбура великої підшкірної вени здатна привести до інволюції притоків сафенних вен на гомілці у більшості пацієнтів (58 \%). Хочемо зазначити, що у великих та грунтовних сучасних наукових оглядах, що стосуються проблем методики термоабляції варикозних вен, аналізу їі ефективності, післяопераційного рецидиву та ускладненням РЧА, чіткої відповіді на отримані результати РЧ моноабляції ми не знайшли $[12,13,14]$. На нашу думку, при відсутності горизонтального скиду крові через перфорантні вени гомілки можна розширити показання до застосування тільки моно РЧА в амбулаторних умовах для більшості хворих, зокрема: для пацієнтів фізичного стану II-III класу за класифікацією Американського товариства анестезіологів (ASA), для пацієнтів похилого віку, з ожирінням, цукровим діабетом та 3 неускладненим перебігом супутньої патології.

При цьому обов'язковою умовою є динамічне та ультразвукове дослідження за станом поверхневої венозної системи, що повинно бути обговорено в угоді з пацієнтом. У випадках відсутності ефекту інволюції колатеральних вен та виявлення причин цього явища (прогресування недостатності перфорантних вен) ставиться питання до застосування додаткових мініінвазивних операцій (мініфлебектомія, ЕХО-склеротерапія колатералей, перфорантних вен) [15]. Як показав наш досвід, такий розподіл операцій на два етапи проти одночасних симультанних втручань має позитивні моменти у плані зменшення тяжкості операцій за шкалою VSS, за показниками якості життя, у запобіганні виникненню рецидивів варикозної хвороби, і що не менше важливо, для розширення показань до виконання РЧА у пацієнтів похилого віку і при супутній поліморбідній патології. 
Висновки. РЧ моноабляція тільки стовбура великої підшкірної вени у більшості пацієнтів (58%) здатна привести до інволюції притоків сафенних вен на гомілці. Це дає можливість за рахунок малотравматичності, скорочення часу операції широко використовувати РЧ моноабляцію у пацієнтів похилого віку та за наявності у хворих поліморбідної супутньої патології.

\section{СПИСОК ЛІТЕРАТУРИ}

1. Gloviczki P. The care of patients with varicose veins and associated chronic venous diseases: Clinical Practice Guidelines of the Society for Vascular Surgery and the American Venous Forum / P. Gloviczki, A. J. Comerota C. Michael // J. Vasc. Surg. 2011. - Vol. 53 (5). - P. 2-48. DOI:10.1016/j.jvs.2011.01.079.

2. Endovascular radiofrequency ablation for varicose veins: An evidence-based analysis. Medical Advisory / Secretariat // Ont. Health Technol. Assess Ser. - 2011. -Vol. 11 (1). - P. 1-93.

3. Sevil F. The effectiveness of endovenous radiofrequency ablation application in varicose vein diseases of the lower extremity / F. Sevil, A. Colak // Cureus. - 2020. - Vol. 12 (4). - P. e7640. DOI: 10.7759/cureus.7640.

4. Bokeria L. A. The optimization of surgical treatment of patients with varicose disease of lower extremities / L. A. Bokeria, M. V. Mikhailichenko, V. I. Kovalenko Russian Medical Journal. - 2015. - Vol. 21 (1). - P.10-14.

5. Hollenbeck B. K. Ambulatory surgery center market share and rates of outpatient surgery in the elderly / B. K. Hollenbeck J. M. Hollingsworth R. L Dunn // Surg. Innov. - 2010. - Vol. 17 (4). - P. 340-345. DOI.org/10.1177/1553350610377211.

6. Khorev N. G. Radiofrequency ablation and traditional phlebectomy in patients with primary venous disease / N. G. Khorev, A. V. Sokolov, M. A. Yelkombayev // Bulletin of Medical Science. - 2019. - Vol. 2 (14). - P. 45-49.

7. Shevchenko Y. L. Basics of clinical phlebology / Y. L. Shevchenko, J. L. Stojko // M.: Shiko. - 2013. - 336 p.

8. Shikhmetov A.N. Results of radiofrequency ablation of subcutaneous veins of the lower extremities in hospital-replacement conditions / A. N. Shikhmetov, N. N. Lebedev, V. A. Shafalinov // Herald of the National Medical-Surgical Center N. I. Pirogov. 2017. - Vol. 12. (4). - P. 81-86.

\section{REFERENCES}

1. Gloviczki, P., Comerota, A.J., \& Michael, C. (2011). The care of patients with varicose veins and associated chronic venous diseases: Clinical Practice Guidelines of the Society for Vascular Surgery and the American Venous Forum. J. Vasc. Surg., 53 (5), 2-48. DOI:10.1016/j.jvs.2011.01.079.

2. Endovascular radiofrequency ablation for varicose veins: An evidence-based analysis. Medical Advisory Secretariat. (2011). Ont Health Technol Assess Ser., 11 (1), 1-93.

3. Sevil, F., \& Colak, A. (2020). The effectiveness of endovenous radiofrequency ablation application in varicose vein diseases of the lower extremity. Cureus., 12 (4),e 7640. DOI: 10.7759/ cureus.7640.

4. Bokeria, L.A., Mikhailichenko, M.V., \& Kovalenko, V.I. (2015.) The optimization of surgical treatment of patients with varicose disease of lower extremities. Russian Medical Journal,
Перспективи подальших досліджень. На основі нашого аналізу результатів РЧА в амбулаторних умовах виникає необхідність розробки чітких показань до вибору виконання тільки РЧА, РЧА в комбінації з іншими мініінвазивними операціями або їх відтермінування залежно від віку хворого, індексу коморбідності та даних УЗД.

9. Kayssi A. Endovenous radiofrequency ablation for the treatment of varicose veins / A. Kayssi, M. Pope, I. Vucemilo // Can. J. Surg. - 2015. - Vol. 58 (2). - P. 85-86. DOI: 10.1503/cjs.014914.

10. Congress of the American West Coast Venous Forum "Challenges and Polemic in Treatment of Venous Pathology" (30 April - 2 May, 2015, Napa, the USA). Novosti Khirurgii. - 2015. - Vol. 23 (5). - P. 582-587.

11. Гощинський В. Б. Застосування PRP та PRF технологий у підготовці до виконання радіочастотної абляції вен у хворих на варикозну хворобу нижніх кінцівок, ускладнену трофічною виразкою / В. Б. Гощинський, Б. О. Мігенько, Ю. Ю. Свідерський // Здобутки клінічної і експериментальної медицини. - 2019. - 2. - C. 99-104 . DOI: I 10.11603/18112471.2019.v0.i2.10376

12. OliveiraI R. A. Evidence for varicose vein treatment: an overview of systematic reviews / R. A. OliveiraI, A. C. Porto, A. C. Mazzucca // Sao Paulo Med. J. - 2018. - Vol. 136 (4). P. 324-332. DOI.org/10.1590/1516-3180.2018.0003240418.

13. Lin F. The management of varicose veins / F. Lin, S. Y. Zhan, Y. Sun // Int. Surg. - 2015. - Vol. 100 (1). - P. 185-189. DOI: 10.9738/INTSURG-D-14-00084.1.

14. Rasmussen L. H. Randomized clinical trial comparing endovenous laser ablation, radiofrequency ablation, foam sclerotherapy and surgical stripping for great saphenous varicose vein / L. H. Rasmussen, M. Lawaetz, L. J. Bjoern // Br. J. Surg. - 2011. - Vol. 98 (8). - P. 1079-1087. DOI: 10.1002/bjs.7555.

15. Carroll C. Clinical effectiveness and cost-effectiveness of minimally invasive techniques to manage varicose veins: A systematic review and economic evaluation / C. Carroll, S. Hummel, J. Leaviss // Health Technol Assess. - 2013. - Vol. 17 (48). - P. 1-141. DOI: 10.3310/hta17480.

21 (1), 10-14.

5. Hollenbeck, B.K, Hollingsworth, J.M., \& Dunn, R.L. (2010). Ambulatory surgery center market share and rates of outpatient surgery in the elderly. Surg. Innov., 2 (4), 340-345. DOI. org/10.1 $177 / 1553350610377211$.

6. Khorev, N.G., Sokolov, A.V., \& Yelkombayev, M.A. (2019). Radiofrequency ablation and traditional phlebectomy in patients with primary venous disease. Bulletin of Medical Science, 2 (14), 45-49.

7. Shevchenko, Y.L., \& Stojko, J.L. (2013). Basics of clinical phlebology. M.: Shiko.

8. Shikhmetov, A.N., Lebedev, N.N., \& Shafalinov, V.A. (2017). Results of radiofrequency ablation of subcutaneous veins of the lower extremities in hospital-replacement conditions. Herald of the National Medical-Surgical Center N.I. Pirogov, 12 (4), 81-86. 
9. Kayssi, A., Pope, M., \& Vucemilo, I. (2015). Endovenous radiofrequency ablation for the treatment of varicose veins. Can. J. Surg., 58 (2), 85-86. DOI: 10.1503/cjs.014914.

10. Congress of the American West Coast Venous Forum "Challenges and Polemic in Treatment of Venous Pathology” (30 April - 2 May, 2015, Napa, the USA). Novosti Khirurgii, 23 (5), 582587.

11. Goshchynsky, V.B., Migenko, B.O., \& Svidersky, U.U. (2019). Zastosuvannia PRP ta PRF tekhnolohii u pidhotovtsi do vykonannia radiochastotnoi abliatsii ven u khvorykh na varykoznu khvorobu nyzhnikh kintsivok, uskladnenu trofichnoiu vyrazkoiu [Application of PRP and PRF technologies in preparation for the implantation of radiofrequency vein ablation in patients with varicosity of the lower extremities, trophic ulcer complications]. Zdobutky klinichnoi i eksperymentalnoi medytsyny Achievements of Clinical and Experimental Medicine, 2, 99-104. DOI :I 10.11603/1811-2471.2019.v0.i2.10376 [in Ukrainian].
12. OliveiraI, R.A., Porto, A.C., \& Mazzucca, A.C. (2018). Evidence for varicose vein treatment: an overview of systematic reviews. Sao Paulo Med. J., 136 (4), 324-332. DOI: org/10.1590/1516-3180.2018.0003240418.

13. Lin, F., Zhang, S., \& Sun, Y. (2015). The management of varicose veins. Int. Surg., 100 (1), 185-189. DOI: 10.9738/INTSURG-D-14-00084.1.

14 Rasmussen, L.H., Lawaetz, M., \& Bjoern, L.J. (2011). Randomized clinical trial comparing endovenous laser ablation, radiofrequency ablation, foam sclerotherapy and surgical stripping for great saphenous varicose vein. Br. J. Surg., 98 (8), 1079-1087. DOI: $10.1002 /$ bjs. 7555 .

15. Carroll, C., Hummel, S., \& Leaviss, J. (2013). Clinical effectiveness and cost-effectiveness of minimally invasive techniques to manage varicose veins: A systematic review and economic evaluation. Health Technol Assess., 17 (48), 1-141. DOI: 10.3310/ hta17480.

Отримано 08.07.2020

Електронна адреса для листування: vgoshchynsky@gmail.com

\section{B. GOSHCHYNSKY, Y. Y. SVIDERSKY, Y. M. HERASIMETS}

I. Horbachevsky Ternopil National Medical University

\section{ABOUT SOME TACTICAL ASPECTS OF THE USE OF RADIOFREQUENCY ABLATION IN THE TREATMENT OF VARICOSE DISEASE OF THE LOWER EXTREMITIES IN OUTPATIENT CARE}

The aim of the work: to give clinical evaluation of the results of using radio frequency ablation in treating varicose veins in order to increase the indications for its implementation in the outpatient setting.

Materials and Methods. During 2016-2019, 928 patients with varicose veins C2-C4 were monitored for classification of CEAP. There were 538 (58 \%) women, and 390 (42 \%) men, aged from 18 to 72 years. To eliminate the vertical reset RFA was used according to the method of VNUS - Closure FAST, using the device COVIDIEN, Medtronics manufacturer.

Results and Discussion. The ultrasound examination of the stem of saphenous veins demonstrated that following RFA, out of 928 patients, 46 (5\%) had the recanalization of GSV after a year, and 84 (9\%) patients - after three years. No reliable difference in the clinical effect was observed in patients with SGV diameters, exceeding $16 \mathrm{~mm}$, in both groups after one and three years. We would like to highlight that after three months of observation, the involution of collaterals was achieved in 58 \% of patients who had undergone monoablation. In 78 (8.4\%) patients were simultaneously performed radiofrequency ablation with sclerotherapy perforant veins on the shin $3 \%$ solution of polydocanol. In 312 patients, after obliterating the trunk of a large subcutaneous vein performed delayed (after 3 months) minimally invasive operations (mini-phlebectomy, foam ECHO obliteration of perforate veins or their radiofrequency ablation stiletto electrode). Radiofrequency monoablation with delayed ultrasound-guided sclerotherapy is a considerably less traumatic and short-term method compared to simultaneous surgical treatment, which provides for its wide application for elderly patients and people with multimorbid concurrent pathology in the outpatient setting.

Key words: radiofrequency ablation saphenous veins; mini-phlebectomy; echo-sclerotherapy. 


\author{
В. Б. ГОЩИНСКИЙ, Ю. Ю. СВИДЕРСКИЙ, Ю. М. ГЕРАСИМЕЦ
}

Тернопольский национальный медицинский университет имени И. Я. Горбачевского МОз Украины

\title{
О НЕКОТОРЫХ ТАКТИЧЕСКИХ АСПЕКТАХ ПРИМЕНЕНИЯ РАДИОЧАСТОТНОЙ АБ.ЯЦИИ В ЛЕЧЕНИИ ВАРИКОЗНОЙ БОЛЕЗНИ НИЖНИХ КОНЕЧНОСТЕЙ В АМБУЛАТОРНЫХ УС.ОВИЯХ
}

\begin{abstract}
Цель работы: дать клиническую оценку результатам радиочастотной абляции в лечении варикозной болезни нижних конечностей с целью расширения показаний к ее выполнению в амбулаторных условиях.

Материалы и методы. Под наблюдением находилось 928 пациентов с варикозными венами C2-C4 по классификации SEAP, из них женщин было 538 (58 \%), мужчин - 390 (42 \%), возраст больных составлял от 18 до 72 лет. Всем больным была выполнена ультразвуковая диагностика для выявления особенности гемодинамических нарушений в конечности. Для устранения вертикального рефлюкса применялась РЧА методом VNUS-Closure FAST, с помощью аппарата COVIDIEN, компании Medtronics.

Результаты исследований и их обсуждение. Анализ результатов моноабляции показал, что через 3 месяца после выполнения процедуры инволюции коллатеральных вен наступила у 538 (58 \%) больных. Таким образом, у большинства больных проблема лечения варикозной болезни была решена применением только РЧА без дополнения другими миниинвазивными операциями. У 78 (8,4 \%) больных была одновременно выполнена РЧА с ЭХО склеротерапией перфорантных вен на голени 3 \% раствором полидоканола. У 312 больных после облитерации ствола большой подкожной вены выполнили отсроченные (после 3 месяцев) малоинвазивные операции (минифлебэктомия, пенная ЭХО облитерация перфорантных вен либо их РЧА стилетным електродом). Таким образом, РЧ моноабляция у большинства больных приводит к инволюции коллатеральных вен, что позволяет расширить показания к этой операции у пациентов старческого возраста, также при наличии полиморбидной сопутствующей патологии. 3 другой стороны, при тех же показаниях альтернативними являются операции на расширенных поверхностных венах в два этапа - РЧ моноабляция, затем отстроченные миниинвазивные операции на варикозных коллатеральных венах. Такое разделение операций на два этапа имеет свои позитивные моменты в плане уменьшения тяжести операций за шкалой VSS и улучшения показателей качества жизни.
\end{abstract}

Ключевые слова: радиочастотная абляция вен; минифлебэктомия; ЭХО-склеротерапия. 